sanaston kehittyminen ja kehittäminen 180o-luvulla. Turun yliopiston suomalaisen ja yleisen kielitieteen laitoksen julkaisuja 77. Turku: Turun yliopisto.

Lieber, Rochelle - Štekauer, Pavol (toim.) 2011: The Oxford handbook of compounding. Oxford University Press: Oxford. https://doi.org/10.1093/oxfordhb/9780199695720.001.0001.

Müller, Peter O. - Ohnheiser, IngeBorg - Olsen, SusAn - RAINER, FrANZ (toim.) 2015-2016: Wordformation. An international handbook of the languages of Europe. I-V. Berlin: De Gruyter Mouton.

Nummila, Kirsi-Maria 2012: Tekijännimet Mikael Agricolan teosten kielessä. Henkilötarkoitteisten johdosten merkitykset, funktiot ja rakenteet. Annales Universitatis Turkuensis C 328. Turku: Turun yliopisto.

Olsen, Susan 2015: Composition. - Peter O. Müller, Ingeborg Ohnheiser, Susan Olsen \& Franz Rainer (toim.), Wordformation. An international handbook of the languages of Europe s. 364-386. Berlin: De Gruyter Mouton.

Pitkänen, KaArina 2008: Suomi kasvitieteen kieleksi. Elias Lönnrot termistön kehittäjänä. Suomalaisen Kirjallisuuden Seuran Tutkimuksia 1164. Helsinki: Suomalaisen Kirjallisuuden Seura.
SAlmi, Heidi 2011: Mikael Agricolan teosten ala-, ylä- ja pää-vartaloiset adpositiot. Annales Universitatis Turkuensis C 307. Turku: Turun yliopisto.

Saukkonen, Pauli 1973: Suomen kielen yhdyssanojen rakenne. - Commentationes Fenno-Ugricae in honorem Erkki Itkonen s. 332-339. Suomalais-Ugrilaisen Seuran Toimituksia 150. Helsinki: Suomalais-Ugrilainen Seura.

Tieteen termipankki. http://www.tieteentermipankki.fi.

Toropainen, TANjA 2014: Ylen-alkuiset sanat Mikael Agricolan teoksissa. - Sananjalka 56 s. 29-49.

_ 2015: Adjektiivialkuiset yhdyssubstantiivit Mikael Agricolan teoksissa. - Sananjalka 57 s. 54-85.

_ 2016: Typografian vaikutus yhdyssubstantiivien oikeinkirjoitukseen Agricolan teoksissa. - Sananjalka 58 s. 175-198.

Tyysteri, Laura 2015: Aamiaiskahvilasta ötökkätarjontaan. Suomen kirjoitetun yleiskielen morfosyntaktisten yhdyssanarakenteiden produktiivisuus. Turun yliopiston julkaisuja C: 408. Turku: Turun yliopisto.

VAittinen, TANJA 2003: Vanhan kirjasuomen yhdysverbit. - Sananjalka 45 s. $118-133$.

2007: Mikael Agricolan teosten yhdysadjektiivit. - Virittäjä 111 s. 523-542.

\title{
Tuoretta tietoa Suomessa puhuttavasta karjalan kielestä
}

Anneli Sarhimaa: Vaietut ja vaiennetut. Karjalankieliset karjalaiset Suomessa. Tietolipas 256. Helsinki: Suomalaisen Kirjallisuuden Seura 2017. 297 s. ISBN 978-952-222-890-1.
Anneli Sarhimaa on julkaissut laajan monografian Suomessa puhuttavasta karjalan kielestä, sen nykytilasta, historiasta sekä karjalaisesta kulttuurista. Teos perustuu tutkimushanke ELDIAn (Euro- 
pean Language Diversity for All) suomenkarjalaa koskevaan tutkimukseen. Monitieteisessä ELDIA-hankkeessa tarkasteltiin vuosina 2010-2013 Euroopan monikielisyyttä ja suomalais-ugrilaisten kielten tilaa kahdeksassa eri maassa. Hankkeessa oli mukana kahdeksan yliopistoa tai tutkimuslaitosta Itävallasta, Ruotsista, Saksasta, Suomesta ja Virosta. Sarhimaa toimi hankkeen johtajana.

ELDIAn tutkimustuloksista on ilmestynyt englanninkielinen teos (Laakso, Sarhimaa, Spiliopoulou Åkermark \& Toivanen 2016). Lisäksi osatutkimusten tuloksia voi lukea internetistä ladattavista raporteista (ks. ELDIA-hankkeen raportit). Koska kuitenkin valtaosa karjalan taitajista on iäkästä väkeä ja koska heillä ei välttämättä ole tietokoneita eikä älypuhelimia, on merkittävää, että heitä koskevan tutkimuksen tulokset on julkaistu suomeksi ja myös muualla kuin internetissä.

Nyt arvioitava teos koostuu kahdeksasta pääluvusta, joista ensimmäinen on luonteeltaan pohjustava. Siinä kerrotaan muun muassa ELDIA-hankkeesta. Toisessa luvussa esitellään karjalankielisten kulttuuria ja kielivähemmistön syntyä ja kolmannessa luvussa niitä historiallisia käänteitä, jotka ovat vaikuttaneet karjalankielisten tilanteeseen. Neljännessä luvussa tarkastellaan karjalankielisten määrän muuttumista ja viidennessä karjalan kielen käyttöaloja. Luvussa kuusi esitellään ELDIA-hankkeen lopputuloksena syntynyt kielen elinvoimaisuusbarometri; seitsemäs luku on kielipoliittinen. Viimeinen luku on kokoava ja tulevaisuuteen tähyävä. Tarkastelen seuraavaksi teosta luvuittain.

\section{Karjalan murteet ja kielen suhde suomeen}

Luvussa 2 esitellään karjalan perinteiset puhuma-alueet Suomessa sekä ne muuttoaallot, joiden myötä Suomeen on muut- tanut karjalankielisiä. Lisäksi valotetaan suomen ja karjalan historiaa, kielten keskinäistä suhdetta sekä esitellään karjalaista kulttuuria. Luvusta ilmenee, että erityisesti Karjalan Kielen Seura on kunnostautunut karjalankielisen kirjallisuuden julkaisijana, joskin valtaosa seuran kustantamista teoksista on kirjoitettu livviksi. Lisäksi esitellään karjalankielisten perinnekulttuuria ja muun muassa karjalankielistä musiikkia Suomessa.

Luku 2 on monella tavalla mielenkiintoinen, mutta ongelmallisena voi pitää sitä, että siinä esitetään monia väitteitä perustelematta niitä lähdeviitteillä. Esimerkiksi karjalan murteita esiteltäessä mainitaan, että "Venäjällä päämurteita erotetaan niin ikään kolme (livvin-, pohjois- ja eteläkarjala), mutta toisin kuin suomalaisessa tutkimuksessa Venäjällä varsinaiskarjalalla tarkoitetaan yksinomaan vienalaismurteita" (s. 29). Tästä tutkijoilla on kuitenkin erilaisia näkemyksiä. Esimerkiksi venäläinen karjalantutkija Pekka Zaikov (2000: 27) määrittelee karjalan päämurteiksi varsinaiskarjalan, livvin ja lyydin. Varsinaiskarjalan hän jakaa edelleen "pohjoiskarjalaan" eli vienalaismurteisiin, "siirtymämurteisiin" sekä "eteläkarjalaan" (mts. 27). Mainittu perinteinen venäläinen kolmijako - varsinaiskarjala (joka kattaa sekä vienan- että eteläkarjalan), livvi ja lyydi - on mainittu myös muun muassa ELDIA-projektin venäjänkarjalan tapaustutkimuksessa (Klementyev, Kovaleva \& Zamyatin 2012: 2-3).

Myös sivun 30 murrekartan yhteydessä olisi hyvä olla lähdeviite, joka osoittaisi, millä perusteella se on laadittu. Muutoin kartta noudattelee Kotimaisten kielten keskuksen verkkosivuilla julkaistua karttaa (ks. Torikka 2004), mutta Sisä-Venäjän kielisaarekkeiden kuvauksesta lukija saa käsityksen, että siellä olisi puhuttu monin paikoin livviä. Tämä ratkaisu olisi kaivannut perusteluja, sillä perinteisesti tverinkarjalan on määritelty edustavan varsinaiskarjalaa (esim. KKM 
1997; Zaikov 2000: 27; Torikka 2004). On toki tiedossa, että Sisä-Venäjälle on muutettu myös esimerkiksi alkuaan livvinkielisestä Salmin pitäjästä (Jeskanen 1998: 256). Sarhimaa on myös aiemmassa yhteisartikkelissaan (Sarhimaa \& Siilin 1994) - kenttähavaintoihinsa perustuen - todennut, että eräissä tverinkarjalaiskylissä kieli muistuttaa enemmän livviä kuin eteläkarjalaa, mutta tämä kaikki olisi ollut hyvä tuoda esiin sivun 30 kar$\tan$ yhteydessä.

Karjalan päämurteita esitellessään Sarhimaa toteaa, että vienankarjala ja livvi ovat normitettuja kielimuotoja, sillä niistä on laadittu esimerkiksi kielioppi ja sanakirjoja. Tässä yhteydessä olisi voinut mainita, että myös tverinkarjala on siinä mielessä normitettu varieteetti, että sillä on julkaistu aapinen (Orlov 1992) ja siitä on tehty sanakirja (Punžina 1994). Lisäksi tverinkarjalankielinen sanomalehti $\mathrm{Ka}$ rielan šana on ilmestynyt 1990-luvulta saakka.

Sivulla 32 Sarhimaa luettelee "kaikki nykyiset itämerensuomalaiset kielet", joiden joukossa ei kuitenkaan mainita kveeniä eikä meänkieltä. Toki ne voidaan lingvistisin kriteerein nähdä suomen varieteetteinakin, mutta koska ELDIAhankkeessa niistä on tehty omat tutkimuksensa (Arola, Kunnas \& Winsa 2011; Räisänen \& Kunnas 2012) ja niitä on käsitelty omina kielinään, olisi johdonmukaista mainita ne myös tässä yhteydessä.

Suomea ja karjalaa erottavien piirteiden yhteydessä sivulla 42 Sarhimaa mainitsee, että "[v]ienalaismurteita lukuun ottamatta kaikissa karjalan murteissa on soinnillisia konsonantteja $(b, d, g, z, \check{z})$ ". Omien tutkimusteni mukaan (esim. Kunnas 2007: 142, 146, 231, 431) ainakin Jyskyjärvellä käytetään kuitenkin laajalti soinnillisia konsonantteja, ja nyt arvioitavassa teoksessa Jyskyjärvi määritellään vienalaismurteen puhuma-alueeksi.

Esitellessään karjalan ja suomen astevaihtelun eroja sivuilla 42 ja 43 Sarhi- maa käyttää lähteenään Kettusen (1960) teosta, mikä on ongelmallista, sillä Sarhimaan käsitys karjalasta on erilainen kuin Kettusen: Kettunen erottaa aunuksenkarjalan ja varsinaiskarjalan omiksi kielikseen. Sarhimaan kuvaus joistakin astevaihtelutapauksista poikkeaakin siitä, mitä Kettunen ja myöhemmin Zaikov (1987) ovat esittäneet - esimerkkinä usson : uššon (s. 43), jonka Sarhimaa yleistää koko karjalaa koskevaksi, mikä ei aiemman tutkimuksen valossa päde kaikkiin karjalan varieteetteihin (ks. Kettunen 1960: 8; Zaikov 1987: 31).

Kohdassa, jossa annetaan esimerkkejä karjalan partisiippimuodoista, mainitaan, ettei karjalassa ole " $v a$-suffiksillisia partisiippimuotoja" (s. 43). Aiemman tutkimuksen perusteella voi kuitenkin päätellä, että $v A$-suffiksia käytetään ainakin vienalaismurteiden passiivin partisiippimuodoissa (esim. on lähettävä matkah; Zaikov 2013: 202).

Alaluvussa 2.2 käsitellään suomen ja karjalan suhdetta toisiinsa. Sarhimaa toteaa (s. 39, alav. 9), että Suomessa puhuttavan karjalan muuttumista toisen maailmansodan jälkeen ovat toistaiseksi tutkineet "aineistopohjaisesti" Raija Pyöli (2015) ja Sanna Lehikoinen (2008). Tätä listaa voi kuitenkin täydentää useilla opinnäytteillä (esim. Korpela 1991; Uusitupa 2011; Massinen 2012; Moshnikov 2014).

Livvin- ja varsinaiskarjalan eroja käsitellessään Sarhimaa toteaa (s. 44), että "livvinkarjala, samoin kuin lyydi, pohjautuvat vahvasti vepsään". Vastikään lyydiläiskysymyksestä väitellyt Miikul Pahomov (2017) katsoo, että livvinkarjalan substraattikieli olisi ennen muuta varhaislyydi, ei vepsä. Karjalan kirjakielestä käytyä keskustelua käsitellessään Sarhimaa kertoo, että niin yhden yhteisen kirjakielen kehittämisestä kuin useiden kirjakielien mallista "löytyy maailmalta sekä onnistuneiksi että epäonnistuneiksi osoittautuneita esimerkkejä" (s. 48). Luki- 
jaa kiinnostaisi, mitä ja minkä kielimuotojen parista nämä esimerkit ovat.

\section{Muutokset syrjityn kieliyhteisön koossa}

Luku 3 esittelee karjalankielisen vähemmistön historiaa sotien ja rajanvetojen valossa. Käy ilmi, että vuodesta 1809 karjalankielisten historia on ollut paljolti syrjäyttämisen historiaa. Erityisen kiinnostava on alaluku 3.5, jossa pohditaan, miksi karjala ei vakiintunut osaksi itsenäisen Suomen kielimaisemaa. Syiksi tälle esitetään muun muassa karjalan kieltä syrjivää tiedepolitiikkaa ja pitkään ja sinnikkäästi toistettua väitettä, jonka mukaan karjala olisi vain suomen murre. E. V. Ahtia kyllä yritti luoda karjalalle kirjakielen 1920-luvulla livvin pohjalta, mutta hanketta vastustettiin suurten murre-erojen ja livvin venäläisvaikutteiden vuoksi: katsottiin, että kirjakielen luominen karjalan varieteeteista "venäläistyneimmän" pohjalta heikentäisi karjalaisten ja suomalaisten "heimoyhteyttä". Lopulta toinen maailmansota lopetti keskustelun kirjakielen kehittämisestä kokonaan. Luku 3 sisältää tärkeää, taustoittavaa tietoa niistä syistä, jotka ovat johtaneet Suomessa puhuttavan karjalan nykytilaan. On tosin huomioitava, että alaluku 3.5 perustuu lähes kokonaan Esa Anttikosken (2000) vertaisarvioimattomaan, kulttuurilehti Careliassa julkaistuun kirjoitukseen.

Luvussa 4 luodaan katsaus siihen, miten karjalankielisten määrä Suomessa on muuttunut toisen maailmansodan jälkeen. Teoksessa esitetään, että Suomessa karjalankielisiä olisi ollut 1940-luvulla vielä 50000 - 60 ooo. ELDIA-hankkeen ja Hämysen (2013) tutkimustuloksiin sekä Karjalan Kielen Seuran arvioon perustuen Sarhimaa esittää, että nykyisin karjalan kieltä "hyvin taitavia" olisi 11000 ja kieltä päivittäin puhuvia 5 ooo. Koko kieliyhteisön esitetään olevan 30 ooo jäsenen kokoinen. Täytyy kuitenkin korostaa, että Sarhimaa itsekin nimeää käsityksen 5000 - 11 ooo puhujasta arvioksi. Tästä huolimatta on selvää, että karjalankieliset eivät ole pienin maamme kotoperäisistä väestöryhmistä. Luvun 4 vahvuus onkin se, että siinä tuodaan selkeästi esiin karjalan kielen asema Suomessa: se on ainoa kotoperäinen kieli, jota ei mainita perustuslaissa ja jonka tukeminen on alkanut vasta 2000 -luvulla.

Alaluvussa 4.1 käsitellään karjalan ISOkoodiasiaa, mikä tulee uudelleen esiin hieman toisteisesti luvussa 7. ISO-koodi on kielikoodi, jolla ihmisten äidinkielet koodataan väestörekisteriin. Ongelmana karjalan kohdalla on se, että koska karjalalle ei ole omaa koodia tilastoissa, karjalan äidinkieliset puhujat näkyvät ryhmässä "muiden kielten puhujat". Vuodesta 2011 karjalan on kuitenkin voinut merkitä äidinkielekseen Suomen väestörekisteriin, ja Sarhimaa mainitsee, että niitä, jotka ovat ilmoittaneet karjalan äidinkielekseen, olisi 123. Kesäkuussa 2017 karjalan äidinkielekseen ilmoittaneita oli kuitenkin jo noin $160^{1}$, joten tilanne on muuttunut hieman vuodesta 2014.

Alaluvussa 4.2 valotetaan niitä syitä, joiden vuoksi monet karjalankieliset luopuivat aikoinaan kielestään. Syiksi esitetään muun muassa syrjintä ja kiusaaminen. Sarhimaa mainitsee yhtenä selityksenä myös karjalankielisten puheyhteisöjen pirstoutumisen heidän menetettyä kotiseutunsa. Kaikkien karjalankielisten osalta väite ei kuitenkaan pidä paikkaansa, sillä yhtäältä Valtimon Rasimäen kylään asutettiin niin paljon suojärveläisiä ja toisaalta Muhokselle niin paljon salmilaisia, että näillä alueilla vanhat karjalaiset yhteisöt säilyivät melko yhtenäisinä sotien jälkeenkin (esim. Hämynen 2013: 204-205; Kunnas 2017). Alaluvussa 4.2 käsitellään myös sitä kielen elvyttämisen kannalta keskeistä asiaa, että mo-

1. Tilastokeskuksen yliaktuaari Markus Rapo sähköpostitse 12.6.2017. 
net ei-karjalaiset kuten myös monet karjalankieliset itse pitävät karjalaa suomen murteena. Tämä osoittaa, että kielitieteilijöiden tutkimustulosten levittämisessä on vielä paljon tehtävää, ennen kuin tieto kielen itsenäisestä statuksesta saavuttaa niin koko karjalankielisen yhteisön kuin valtaväestönkin.

\section{Kielen käyttöalat ja elinvoimaisuus}

Luku 5 esittelee ELDIAn tutkimustuloksia siltä osin, kuinka paljon karjalaa puhutaan, luetaan ja kirjoitetaan sekä miten kielen käyttö vaihtelee esimerkiksi ikäryhmittäin. Kirjoittaja on päätynyt kertomaan tutkimuksensa aineistosta vasta tässä luvussa. Aineisto on suuri: se koostuu kyselylomakevastauksista sekä ryhmäkeskusteluista. Kyselylomakkeen on täyttänyt 356 vastaajaa, jotka on valittu stratifioidulla satunnaisotannalla pitäjäseurojen, Karjalan Kielen Seuran ja Karjalan Sivistysseuran jäsenistä. Harmillisesti teoksesta ei kuitenkaan ilmene, kuinka monta ryhmäkeskustelua on tehty, kuinka monta osallistujaa niissä on ollut, missä ja millä kielellä ne on tehty ja kuinka monta tuntia haastatteluaineistoa on. Myöskään litterointiperiaatteita ei esitellä. Karjalantaitoista lukijaa saattaakin ihmetyttää, miksi samassa esimerkissä käytetään affrikaatan merkitsemiseen $c c$ :tä, $c$ :tä ja $\check{c}$ :tä (s. 201) - etenkin kun nykykarjalan ortografiassa käytetään johdonmukaisesti č:tä (esim. Pyöli 2011: 10; Zaikov 2013: 12).

Luvusta 5 ilmenee, että karjalaa hyvin puhuvia ei ole ainoastaan vanhimmassa ikäryhmässä ja että kielen ymmärtäminen on yleisempää kuin puhuminen. Karjalan kielellä kirjoittaminen on vastaajien keskuudessa harvinaista: puolet vastaajista ilmoittaa, ettei osaa kirjoittaa karjalaksi lainkaan. 30-49-vuotiaiden vastaajien keskuudessa on Sarhimaan mukaan ollut eräänlaisia "avainlapsia", jotka ovat alkaneet puhua karjalaa nuoremmille sisaruk- silleen (s. 160-161). Nykylasten vanhemmissa on myös karjalaa osaavia, mutta kielen käyttö kotona koetaan "hassuksi" tai "vaikeaksi", sillä kieli yhdistyy isovanhempien sukupolveen ja monilta puuttuu malli karjalan käyttämisestä kotikielenä. Nuorimmat karjalaa kotikielenään käyttävistä ovat Sarhimaan mukaan pääsääntöisesti yli 5o-vuotiaita (s. 167). Luvussa tuodaan esiin myös, että karjalaa käytetään nykyisin aktiivisesti internetin keskustelupalstoilla ja karjalan kieleen liittyvissä sosiaalisen median ryhmissä. Sivulla 183 Sarhimaa nimittää karjalankielisiä internetryhmiä sosiolingvistisiksi verkostoiksi, vaikka vakiintunut nimitys näille lienee sosiaalinen verkosto (esim. Lappalainen 2004).

Luvussa 6 esitellään ELDIA-projektin yhteydessä kehitelty EuLaViBar (The European Language Vitality Barometer), joka on kielen elinvoimaisuusbarometri, ja tarkastellaan Suomessa puhuttavaa karjalaa sen valossa. Ilmenee, että karjalan kielen taidon kehittämisen ja ylläpitämisen edellytykset Suomessa ovat heikot ja että yhteiskunnan tuki karjalan käyttämiselle koetaan vähäiseksi. Sivulla 198 Sarhimaa luettelee ansiokkaasti, miten karjalan kieltä voitaisiin Suomessa elvyttää. Hän tuo esiin muun muassa yhteisöllisyyden kasvattamisen merkityksen: lasten, nuorten, aikuisten ja vanhusten karjalankielisten yhteisöjen tulisi verkostoitua keskenään. Myös karjalan kieleen ja kulttuuriin liittyvää toimintaa tulisi kehittää "nykyaikaisia kiinnostuksen kohteita vastaaviksi". Sarhimaa esittää, että karjalankielisen lehden, Karjal Žurnualun, tulisi ilmestyä verkkoversion lisäksi paperiversiona. Näin on kuitenkin tapahtunut jo usean vuoden ajan.

\section{Kielipolitiikkaa}

Luku 7 on omistettu kielipolitiikalle, ja siinä kerrotaan, miten Suomen kielipolitiikka on vaikuttanut karjalan tilantee- 
seen ja elvyttämispyrkimyksiin. Luku on tärkeä, sillä se valottaa perin pohjin sitä, miten vähälle huomiolle karjala on jäänyt lakeja kirjoitettaessa. Sarhimaa perustelee hyvin, miksi karjalalle tulisi laatia kielipoliittinen ohjelma, virallinen elvytysohjelma sekä oma kielilakinsa. Luvussa 7 kerrotaan myös karjalankielisten seurojen toiminnasta ja muun muassa toimenpideohjelmasta, joka tähtää eteläkarjalan voimaannuttamiseen. Lisäksi kirjoittaja tuo esiin niitä ongelmia, joita karjalan kouluopetukseen Suomessa liittyy. Yksi esimerkki tästä on se, että on hankala saada kokoon riittävän suuria ryhmiä, jotta opetus voitaisiin järjestää. Lisäksi Suomessa ei kouluteta karjalan kielen opettajia eivätkä Venäjän puolella valmistetut karjalankieliset oppimateriaalit sellaisinaan sovi suomalaiseen kulttuuriin. Sarhimaa toteaa myös, että oppimateriaalit tulisi laatia suoraan sellaisiksi, että ne soveltuvat etä- ja itseopiskeluun.

Teoksen viimeisessä luvussa esitetään kokoavasti, että karjalan elvytyksen edellytykset ovat niin yhteiskunnan taholta tuleva tuki kuin karjalankielisen yhteisön oma aktiivisuus ja samanmielisyyskin.

\section{Lopuksi}

Kirja on kirjoitettu pääosin sujuvasti, mutta lukuihin 5 ja 6 on jäänyt muutamia epäselviä kohtia. Lisäksi teoksen lähdeviitteiden merkintä on vaihtelevaa. Kirjoittaja mainitsee sivulla 12, että kun "tekstissä ei ole mainittu lähdettä, esitetyt tulokset - - perustuvat ennen muuta ELDIAssa tehtyyn tutkimustyöhön". Kuitenkin teoksessa on useita kohtia (esim. s. $45,88,89$ ), joista lähdeviite tai -viitteet puuttuvat mutta jotka eivät voi perustua ELDIA-hankkeen tuloksiin. Muutamissa kohdissa viitteen ala on merkitty epäselvästi (esim. s. 95).

Vaikka olen esittänyt edellä joitain kriittisiä huomioita tekstin yksityiskohdista, kaiken kaikkiaan teos Vaietut ja vaiennetut on merkittävä keskustelunavaus ja tieteellinen teko. Yliopistoopetukseen on kaivattu jo pitkään suomenkielistä kokonaisesitystä karjalasta, yhdestä Suomen kotoperäisestä kielestä. Tähän tarpeeseen arvioitava teos vastaa hyvin. Toivottavasti karjalankielinen vähemmistö Suomessa tulee teoksen myötä tutummaksi kaikille suomalaisille. Erityisen toivottavaa olisi, että myös päätöksentekijät tutustuisivat Sarhimaan kirjaan ja ymmärtäisivät, miten väärin yhtä Suomen kielivähemmistöistä on historian aikana kohdeltu.

NiIna Kunnas etunimi.sukunimi@oulu.fi

Kirjoittaja on suomen kielen yliopistonlehtori Oulun yliopistossa ja suomen kielen professori Sámi allaskuvlassa.

\section{Lähteet}

Antтikoski, Esa 2000: Karjalan kirjakielikysymys Suomen karjalaisliikkeen toiminnassa. - Carelia 9 s. 36-41.

Arola, Laura - Kunnas, NiIna Winsa, BIRger 2011: Meänkieli in Sweden. An overview of a language in context. Working Papers in European Language Diversity 6. Research consortium ELDIA. https://phaidra.univie. ac.at/view/o:103155 (15.2.2018).

ELDIA-hankkeen raportit. Studies in European Language Diversity. http://phaidra. univie.ac.at/o:80726 (15.2.2018).

HÄMYNEN, TAPIO 2013: Rajakarjalaisen kieliyhteisön rapautuminen ja karjalankielisten määrä Suomessa. - Pekka Suutari (toim.), Karjala-kuvaa rakentamassa s. 182-213. Helsinki: Suomalaisen Kirjallisuuden Seura.

Jeskanen, Matti 1998: "Karielat Hormilla keššeššă". Sisä-Venäjän, erityisesti Tverin alueen karjalaiset. - Pekka Nevalainen ja Hannes Sihvo (toim.), Karjala. Historia, 
kansa, kulttuuri s. 255-276. Suomalaisen Kirjallisuuden Seuran Toimituksia 705. Helsinki: Suomalaisen Kirjallisuuden Seura.

Kettunen, LAURI 1960: Suomen lähisukukielten luonteenomaiset piirteet. Suomalais-Ugrilaisen Seuran Toimituksia 119. Helsinki: Suomalais-Ugrilainen Seura.

KKM = BUBRIH, D. V. - BELJAKov, A. A. - Punžina, A. V. 1997: Karjalan kielen murrekartasto. Toimittanut Leena Sarvas. Helsinki: Kotimaisten kielten tutkimuskeskus \& Suomalais-Ugrilainen Seura.

Klementyev, Yevgeniy - Kovaleva, Svetlana - Zamyatin, KonstanTIN 2012: The Karelian language in Russia. An overview of a language in context. Working Papers in European Language Diversity 12. Research consortium ELDIA. https://fedora.phaidra.univie. ac.at/fedora/get/o:105164/bdef:Content/ get (20.11.2017).

Korpela, EIla 1991: Karjalan kielen säilymisestä Suomussalmen vienalaiskylissä. Suomen kielen pro gradu -tutkielma. Oulun yliopisto.

Kunnas, Ninna 2007: Miten muuttuu runokylien kieli. Jälkitavujen A-loppuisten vokaalijonojen variaatiosta vienalaismurteissa. Acta Universitatis Ouluensis B 78 . Oulu: Oulun yliopisto.

_ 2017: Monikielisyys ja monikulttuurinen naapuruus pohjoisessa. Tapaustutkimus Oulun seudun karjalankielisistä Esitelmä symposiumissa Karjalankieliset identiteetit rajalla. Joensuu, 27.1.2017.

LaAkso, Johanna - Sarhimaa, Anneli - Spiliopoulou Åkermark, Sia - Toivanen, Reetta 2016: Towards openly multilingual policies and practices. Assessing minority language maintenance across Europe. Bristol: Multilingual Matters.

Lappalainen, Hanna 2004: Variaatio ja sen funktiot. Erään sosiaalisen verkoston jäsenten kielellisen variaation ja vuoro- vaikutuksen tarkastelua. Suomalaisen Kirjallisuuden Seuran Toimituksia 964. Helsinki: Suomalaisen Kirjallisuuden Seura.

Lehikoinen, SAnna 2008: Karjalaa vai suomea? Karjalan kielen säilymisestä suojärveläissyntyisillä siirtokarjalaisilla. Suomen kielen pro gradu -tutkielma. Joensuun yliopisto.

Massinen, Henna 2012: Yleis- ja erikoisgeminaatio Ilomantsin karjalankielisten siirtolaisten idiolekteissa. Suomen kielen pro gradu -tutkielma. Itä-Suomen yliopisto.

Moshnikov, ILJA 2014: NUT-partisiipin variaatio Ilomantsin rajakarjalaismurteessa. Suomen kielen pro gradu -tutkielma. Itä-Suomen yliopisto.

Orlov, Minail M. 1992: Bukvari. Helsinki: Tverin karielan kulturan občestvo \& Karjalan Sivistysseura.

PAномоv, Miı́l 2017: Lyydiläiskysymys. Kansa vai heimo, kieli vai murre. Helsinki: Helsingin yliopisto \& Lyydiläinen Seura.

Punžina, Aleksandra V. 1994: Slovar' Karel'skogo jazyka (tverskie govory). Petroskoi: Karelija.

Pyöli, RAIJA 2011: Livvinkarjalan kielioppi. Helsinki: Karjalan Kielen Seura. 2015: Salmilaisten kieli. - Jukka Kokkonen (toim.), Rajoil da randamil. Salmi ja salmilaiset 1617-1948 s. 499-525. Saarijärvi: Salmi-Säätiö.

RÄIsänen, Anna-Kaisa - Kunnas, NiINA 2012: Kven in Norway. An overview of a language in context. Working Papers in European Language Diversity. Research consortium ELDIA. https://phaidra. univie.ac.at/view/o:105485 (15.2.2018).

SarhimaA, Anneli - Sillin, Lea 1994: "Pasportas on kirjutettu mie olen karjalan'e". - Tapio Hämynen (toim.), Kahden Karjalan välillä. Kahden Riikin riitamaalla s. 267-278. Joensuun yliopiston humanistinen tiedekunta.

TorikKa, MarJa 2004: Karjala. Kieli, murre 
ja paikka. Kotimaisten kielten tutkimuskeskuksen julkaisuja 129. Helsinki: Kotimaisten kielten tutkimuskeskus. http://scripta.kotus.fi/www/verkkojulkaisut/julk129/karjala_sisalto.shtml (20.11.2017).

Uusitupa, Milla 2011: Avoimet persoonaviittaukset rajakarjalaismurteissa. Suomen kielen pro gradu -tutkielma. Itä-Suomen yliopisto.

ZAiкоv, Pекка 1987: Karjalan kielen murre- oppia. Petroskoi: Petroskoin valtionyliopisto.

— 2000: Glagol v karelskom jazyke. Grammatitšeskie kategorii litsa-tšisla, vremeni i naklonenija. Petrozavodsk: Izdatelstvo Petrozavodskogo gosudarstvennogo universiteta.

— 2013: Vienankarjalan kielioppi. Lisänä harjotukšie ta lukemisto. Helsinki: Karjalan Sivistysseura.

\section{Perustietoa Unkarin paikannimistä}

\author{
István Hoffmann, Anita Rácz \& Valéria \\ Tóth: History of Hungarian toponyms. \\ Berlin: Buske 2017. 310 s. \\ ISBN 978-3-87548-844-9.
}

Käsillä olevan teoksen nimi, History of Hungarian toponyms, on yksinkertaisuudessaan erinomaisesti valittu: teos on ensimmäinen englanniksi julkaistu yleisesitys Unkarin paikannimistöstä, ja sen tarkoituksena on toimia johdatuksena unkarilaiseen paikannimistöön sekä innoittaa onomastista tutkimusta ja ajattelua myös Unkarin ulkopuolella. Kirjan tekijät - István Hoffman, Anita Rácz ja Valéria Tóth - ovat unkarilaisen onomastiikan laaja-alaisia asiantuntijoita Debrecenin yliopistosta.

Kirjan yksityiskohtaisesta sisällysluettelosta saa hyvän käsityksen kirjan sisällöstä ja painotuksista. Teos jakautuu kuuteen päälukuun. Ensimmäisessä esitellään paikannimistön tutkimuksen teoriaa. Toisessa pääluvussa käydään läpi Unkarin ja unkarilaisten historiaa sekä paikannimistön tutkimuksen lähteitä.
Luvuissa III-VI käsitellään itse paikannimistöä. Makrotoponyymeistä nostetaan esiin vesistöjen ja alueiden nimet, mutta mikrotoponyymejä käsitellään vähemmän yksityiskohtaisesti. Kokonaisuuden laajuuden kannalta rajaukset ovat kuitenkin perusteltuja, sillä tarkoituksena on ollut laatia laajahkolle lukijakunnalle suunnattu synteesi unkarilaisesta paikannimistöstä.

\section{Paikannimistön tutkimuksen taustaa ja lähteitä}

Teoriaa esittelevä aloitusluku toimii johdatuksena nimistöntutkimukseen tieteenalana. Luvussa esitellään paikannimistön tutkimuksen keskeisiä käsitteitä unkarilaisen paikannimiaineiston kautta. Historiallista taustaa esittelevässä toisessa luvussa käydään läpi Unkarin historiaa sekä paikannimistön tutkimuksen lähdeaineistoja. Yksityiskohtaisuudessaan historiallinen osuus taustoittaa asutusnimistön kehitystä käsittelevää viidettä lukua. Suomalaista lukijaa kiinnostavat erityisesti unka- 